\title{
Use of TOF-SIMS to Study Adsorption and Loading Behavior of Methylene Blue and Papain in a Nano-Porous Silicon Layer
}

\author{
Ivan M. Kempson, ${ }^{\mathrm{a}, \mathrm{b}}$ Timothy J. Barnes, ${ }^{\mathrm{a}}$ and Clive A. Prestidge ${ }^{\mathrm{a}}$ \\ ${ }^{a}$ Ian Wark Research Institute, University of South Australia, Mawson Lakes, SA, Australia \\ ${ }^{\mathrm{b}}$ Institute of Physics, Academia Sinica Nankang, Taipei, Taiwan
}

TOF-SIMS was applied to study the cross-sectional distribution of methylene blue and papain in porous silicon layers. Elemental and molecular information were used to study their distributions in the porous region and the chemistry of their adsorption. Methylene blue $(\mathrm{MW}=284 \mathrm{Da})$ penetrated to the base to the pores. Positive ions $\left(\mathrm{SiCH}_{3}^{+}\right)$suggest methylene blue binds to the substrate via its methyl groups. Negative fragments $\left(\mathrm{SiOSH}_{3}^{-}\right.$ and $\mathrm{SiO}_{2} \mathrm{SCH}^{-}$) also suggested chemisorption via $\mathrm{O}$ bridging of the substrate $\mathrm{Si}$ and methylene blue S. The larger Papain molecule $(23,406 \mathrm{Da})$ distributed itself in a similar manner to methylene blue demonstrating larger molecules can be effectively incorporated into such pore structures. (J Am Soc Mass Spectrom 2010, 21, 254-260) @ 2010 American Society for Mass Spectrometry

$\mathrm{P}$ orous silicon $(\mathrm{pSi})$ is a nanostructured material with $2-50 \mathrm{~nm}$ pores and has been investigated for use in a range of applications, including; optical [1, 2], biosensing [3], radiotherapy (brachytherapy) [4], and the delivery of active pharmaceutical ingredients $[5,6]$. The ongoing interest in $\mathrm{pSi}$ for use as a therapeutic delivery system is due to the large internal surface area available, the readily modified surface chemistry [7] and, in particular, the excellent in vivo biodegradation and biocompatibility (low toxicity) of the silicon substrate, hydrolysing to form orthosilicic acid, which is readily excreted [8]. The loading dynamics of molecules into a pSi matrix is dependent on wetting and the size of the pores. Likewise, the interaction between a loaded molecule and the pSi substrate is of interest, particularly in the case of protein based therapeutics, whose bioactivity is dependent on remaining in a specific 3D conformation.

TOF-SIMS analysis provides information regarding elemental and molecular species present in a sample surface (i.e., within 1-1.5 $\mathrm{nm}$ ) with high mass resolution (up to $\sim 10,000 \mathrm{~m} / \Delta \mathrm{m}$ ) and spatial resolution for imaging ( $\sim 1$ micron). Molecular and elemental information is obtained for organic and inorganic materials providing a powerful technique to image organic compounds associated with inorganic substrates or vice versa [9, 10]. This has been demonstrated by imaging solid-state pharmaceutical formulations [11-14], however, to date this has not been extended to porous silicon substrates.

Address reprint requests to Dr. I. M. Kempson, Ian Wark Research Institute, University of South Australia, Mawson Lakes, SA 5095, Australia. E-mail: Ivan.Kempson@unisa.edu.au
In this study, TOF-SIMS was used to map the distribution of methylene blue and papain across porous silicon layers after loading from aqueous solution. Methylene blue $\left(\mathrm{C}_{16} \mathrm{H}_{18} \mathrm{~N}_{3} \mathrm{~S}^{+}\right.$, $\left.\mathrm{MW}=284.12 \mathrm{~g} / \mathrm{mol}\right)$ is a relatively small organic dye molecule commonly used in adsorption studies and can be considered analogous to therapeutic molecules. A molecular mass of 284 $\mathrm{g} / \mathrm{mol}$ is within a reasonable mass range for a TOFSIMS' $\mathrm{Ga}^{+}$primary ion beam and can be easily and uniquely identified without interference or confusion from spectral peaks originating from the silicon substrate or in the instance of organic contamination. This molecule was chosen for its convenience, and to assess the ability to use smaller organic fragments to reflect the distribution of the molecule of interest. This is important to be able to extend this work to studying larger molecules, such as proteins and enzymes of pharmaceutical interest, which will not provide a molecular ion in TOF-SIMS. In contrast to methylene blue, papain is a much larger molecule, detailed elsewhere [15], comprising 212 residue units in two domains, giving a molecular weight of $23,406 \mathrm{~g} / \mathrm{mol}$. Papain is a cysteine protease hydrolase enzyme present in papaya. This molecular weight is far greater than can be detected with TOF-SIMS, however, fragmentation products can be detected. Smaller organic fragments can be compared with the distribution of methylene blue to investigate similarities and differences in loading that may result from a much larger molecule. These probe molecules have been specifically chosen to differentiate the influence of size, structure and chemistry on loading and distribution into $\mathrm{pSi}$. 


\section{Experimental}

\section{Materials}

Porous silicon wafers $(\mathrm{p}+$ silicon wafers, $0.005-0.020$ $\Omega . \mathrm{cm}, 70 \%$ porosity, $10 \mathrm{~nm}$ pores) were prepared by electrochemical anodization (hydrofluoric acid/ethanol electrolyte) [7], and were used as supplied by pSiMedica Ltd. (Malvern, UK). Methylene blue (as a chloride salt, Sigma Aldrich, Sydney, Australia) and papain from Carica papaya (Fluka, BioChemika, Switzerland) were used as obtained without further purification. Ultra high purity deionized water (Milli-Q, Millipore, Sydney, Australia) was used throughout all experiments.

\section{Preparation of Loaded Porous Silicon Wafers}

The porous silicon wafers have a porous region spanning a depth of $\sim 100$ micron into the surface of the wafer with $10 \mathrm{~nm}$ pores. The methylene blue (MB, $\mathrm{C}_{16} \mathrm{H}_{18} \mathrm{~N}_{3} \mathrm{~S}, \mathrm{M}_{\mathrm{w}}=284.12 \mathrm{~g} / \mathrm{mol}$, Figure 1) and papain (212 amino acid residues, $\mathrm{M}_{\mathrm{w}}=23,406 \mathrm{~g} / \mathrm{mol}$ ) were loaded into the pSi wafers $\left(\sim 0.5 \mathrm{~cm}^{2}\right)$ using an immer- sion method, whereby the wafer sections were placed in $10 \mathrm{~mL}$ of the appropriate aqueous solution $(\sim 0.8$ $\mathrm{mg} / \mathrm{mL}$ and $20 \mu \mathrm{g} / \mathrm{mL}$, respectively) for $\sim 1 \mathrm{~h}$ before rinsing with fresh Milli-Q water and dried under nitrogen. Similarly, a blank wafer (i.e., not exposed to MB or papain) was prepared in Milli-Q water for $1 \mathrm{~h}$, then dried under nitrogen. Wafers were fractured immediately before analysis and mounted in a clamp to hold the wafer perpendicular to the analysis plane to analyze the wafer cross-section.

\section{Time-of-Flight Secondary Ion Mass Spectrometry (TOF-SIMS)}

A Physical Electronics PHI TRIFT II TOF-SIMS with a pulsed liquid metal Ga ion gun was used with an accelerating potential of $15 \mathrm{kV}$ to optimize for spectral resolution (typically between 3000 and $5000 \mathrm{~m} / \Delta \mathrm{m}$ ) and $25 \mathrm{kV}$ to optimize spatial resolution $(\sim 1$ micron and $\sim 1500-3000 \mathrm{~m} / \Delta \mathrm{m})$. Data were acquired for a mass range of $0-1000 \mathrm{Da}$. No significant spectral information was observed for mass-to-charge $(\mathrm{m} / \mathrm{z})$ ratios
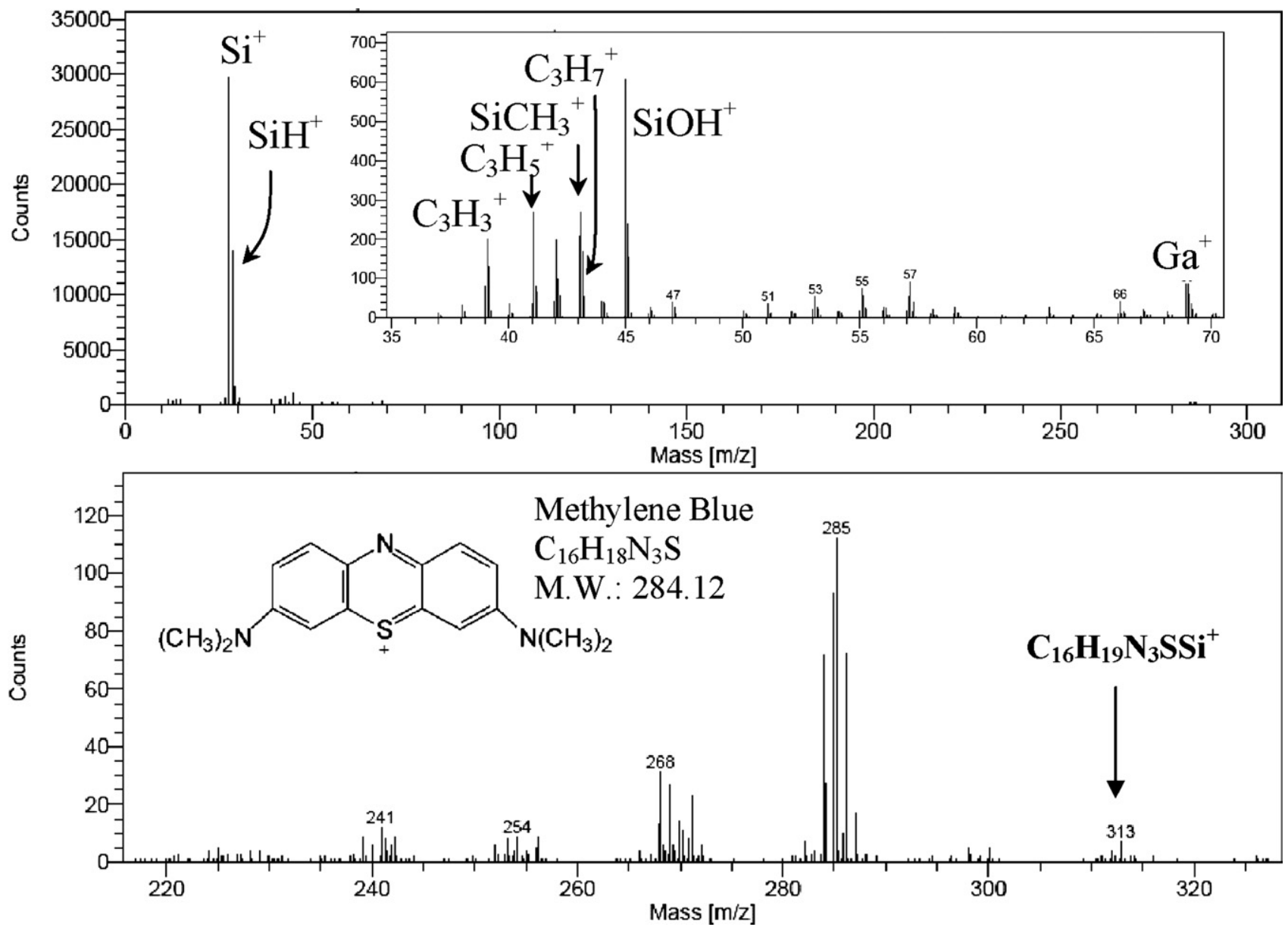

Figure 1. Positive ion TOF-SIMS spectrum from the porous region of a methylene blue loaded silicon wafer, dominated by $\mathrm{Si}^{+}, 27.97 \mathrm{Da}$. Other peaks are indicative of the methylene blue parent ion (clustered around $286 \mathrm{Da}$ ), its fragments (such as various $\mathrm{C}_{\mathrm{x}} \mathrm{H}_{\mathrm{y}}^{+}$peaks), and the substrate (such as $\mathrm{SiOH}^{+}$at $\left.44.98 \mathrm{Da}\right) . \mathrm{Ga}^{+}(68.92 \mathrm{Da})$ originates from the primary ion source. 
greater than $\sim 300 \mathrm{Da}$. Negative and positive ions were acquired; however the positive ion spectra yielded significantly more information. Analysis was performed with 20-ns 600-pA DC pulses at a rate of $11 \mathrm{kHz}$ focused onto the sample. This translates to a primary ion dose of $4.9 \times 10^{8}$ ions for an analysis of 10-min duration. Doses per unit area are dependent on the time of the acquisition and the area rastered, however, static limits were adhered to. It is important to note that the detection sensitivity between species is highly variable and matrix dependent. Therefore, signal intensities from two species of equal magnitude do not necessarily represent equivalent concentrations. Similarly, different materials but with equal concentrations can produce different signal intensities. This work only discusses changes in relative signal intensities from samples of the same matrix. Signal intensities were calculated as a fraction of the total ion counts. All TOF-SIMS images produced were normalized by the total ion image (pixel-by-pixel division) to remove topographic and secondary ion yield effects. Line scans were generated from these normalized images and scaled to the fragments' maximum intensity.

For this study, six samples were analyzed: silicon wafers spin-coated with $\mathrm{MB}$ and papain; a fresh $\mathrm{pSi}$ wafer (not exposed to water); a wafer exposed to only the Milli-Q water; and each wafer section exposed to $\mathrm{MB}$ and papain, respectively. Although results from the spin-coated and two "blank" wafer sections are not presented here, their analysis assisted in the spectral interpretation and to ascribe peaks observed in the MB-loaded pSi wafer TOF-SIMS data, particularly whether observed signals were due to organic loading rather than contamination or other artefacts that may have been incorporated during the manufacture process, handling, or storage.

\section{Results and Discussion}

A positive ion spectrum from the methylene blue loaded region of a porous silicon wafer is shown in Figure 1. Several prominent peaks in the negative and positive ion spectra indicate the silicon substrate. $\mathrm{Si}^{+}$, $\mathrm{SiO}^{+}, \mathrm{SiO}_{2}^{-}$, and $\mathrm{SiO}_{3}^{-}$were present as expected for silica materials [16], conversely, however, for the porous silicon material studied here, $\mathrm{SiOH}^{+}, \mathrm{SiO}_{2} \mathrm{H}^{-}$, and $\mathrm{SiO}_{3} \mathrm{H}^{-}$peaks were more prominent. This effect has been ascribed to the hydrolysis of the silicon surface and formation of silanol functional groups during exposure to aqueous environments in the sample preparation. There is also evidence of fluorination of the surface from the etching process by way of TOF-SIMS signals due to $\mathrm{SiF}^{-}$.

Methylene blue was indicated by the group of fragments dominated by the peak at $285 \mathrm{Da}$. The cationic molecular ion occurs at $284 \mathrm{Da}\left([\mathrm{MB}]^{+}\right)$but the $285 \mathrm{Da}$ $\left([\mathrm{MB}+\mathrm{H}]^{+} \bullet\right.$ ) peak had a factor of $\sim 2$ more counts. This can be ascribed to a combination of $(\mathrm{MH})^{+}$and/or $(\mathrm{M}) \mathrm{H}^{+}$due to a reductive process and isotopic $\mathrm{M}^{+}$[17].
The 284, 285, and 286 Da peak intensities are highly dependent upon matrix effects. In MALDI, the [M + $1] / M$ peak ratio was shown to vary from $34 \%$ to $123 \%$, depending on matrix-to-analyte ratios [17]. Such fragment intensities may also depend on the micro-structure of the fractured surface [18] and the primary ion properties $[19,20]$. The cationic dye fragment possesses a nonlocalized charge due to resonance forms of methylene blue with a positively charged $S$ and a positively charged quaternary ammonium group. The groups of peaks adjacent to the molecular cluster, at lower mass units, reflect the sequential loss of small fragments such as methyl groups from the molecule. The mass fragment at $39.02 \mathrm{Da}$ can be indicative of $\mathrm{C}_{3} \mathrm{H}_{3}$ fragments generated from the aromatic organic species [21], which would be conducive with the chemical structure of methylene blue.

Images of several fragments at the $\mathrm{pSi}$ sample surface are given in Figure 2. The total ion yield (TIY) demonstrates some topographic features induced in the fracturing of this surface. Secondary ion yield effects are normalized out for abundant species such as $\mathrm{Si}^{+}$. For low yielding species, some of these topographicallyinduced features can remain. Some apparent 'noise' was induced in imaging low molecular weight organic peaks, such as $\mathrm{C}_{3} \mathrm{H}_{5}$ etc. due to topographic broadening of peaks, which induced slight overlaps with $\mathrm{Si}-\mathrm{C}$ based fragments. Region of interest analysis was used to remove these effects for confirming the identity of peaks and discounting contamination. Line scans of the porous region of the blank pSi wafer shown in Figure 3 are given in Figure 4. No changes in the relative $\mathrm{Si}^{+}$or $\mathrm{SiOH}^{+}$signal were observed through the extent of the porous region. A subtle decrease in the relative signal of $\mathrm{SiH}^{+}$could indicate a slight change in the silicon chemistry at the base of the pore, however this change is minor and probably does not reflect a change significant enough to result in such a dramatic effect in the organic distributions (Figure 5).

The image of organic peaks indicative of methylene blue in a mass range of $235-290 \mathrm{Da}$ is provided, as well as a selection of smaller organic fragments. It is important to note that these organic peaks were not present in the blank wafer or the water exposed wafer. The distribution of methylene blue and the associated organic fragments are seen to deposit at the deepest pore regions, exemplified in Figure 5. Such a distribution could be induced by either different chemistry in the deeper region (which is not obviously apparent), or as an artefact due to the loading dynamics of the methylene blue or subsequent washing. Additionally, restriction of movement in the bottom of pores may increase residence time and likelihood of binding. Pore constriction at greater depths may also offer a means for this observation to occur. The possibility of limited diffusion of $\mathrm{MB}$ from out of the shallow pore regions during drying of the wafer cannot be discounted. However, in this case, it would be expected that an intense deposit of 


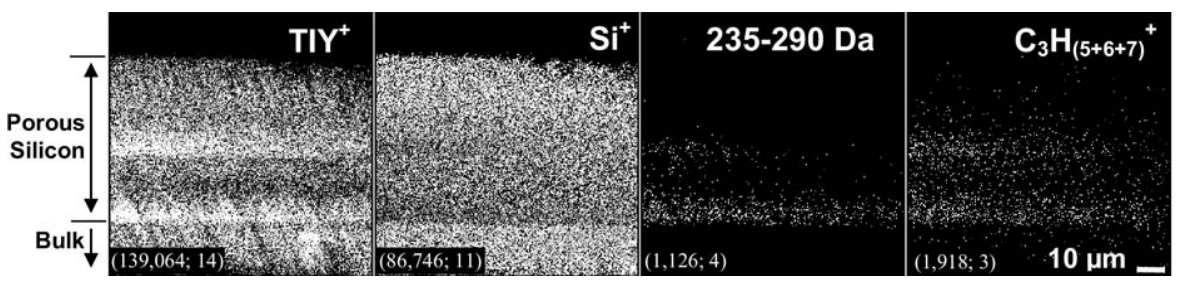

Figure 2. Positive ion images of a methylene blue loaded wafer. The total ion yield demonstrates some topographic effects, but the $\mathrm{Si}^{+}$image highlights the porous and bulk region of the wafer. Images of organic peaks demonstrate methylene blue penetration and adsorption into the deepest regions of the porous layer. Numbers in parentheses indicate: (total ion counts; maximum count per pixel).

methylene blue would be observed at the wafer surface, which has not been detected here.

An added benefit of analyzing such systems with TOF-SIMS is the potential for gaining chemical information identifying the association of specific functional groups involved in any chemical bonding. Molecular ions, for instance, can reveal fragments generated from a combination of the substrate and deposited material. An interesting peak in Figure 1 occurs at $313 \mathrm{Da}$, ascribed to $(\mathrm{MSi}) \mathrm{H}^{+}$or $(\mathrm{MSiH})^{+}$suggesting that the methylene blue may have chemically interacted and bound to the substrate. The presence of $\mathrm{SiCH}_{3}^{+}$as a prominent peak suggests this interaction has occurred with the dye's methyl groups. This fragment can also originate due to siloxane contamination, however, in this case, can be discounted, confirmed by the absence of other indicative peaks in the positive and negative spectra, particularly $\mathrm{SiC}_{3} \mathrm{H}_{9}^{+}$at $73.047 \mathrm{Da}$. These $\mathrm{Si}$ containing fragments are spatially distributed in a correlated manner to the methylene blue molecular ions.

An additional aspect noteworthy is the presence of $\mathrm{Cl}^{-}$in the negative ion spectra (not shown) in the porous region. $\mathrm{Cl}^{-}$was observed in the blank wafer as well as the loaded wafer. This can originate from $\mathrm{HCl}$ existing in small quantities in the HF used for the silicon anodization process. Additionally, further $\mathrm{Cl}$ could originate from the methylene blue chloride salt used in the preparation of the solution. Free anionic chloride and/or fluoride ions could interact with the substrate or cationic dye and impose competitive processes in the adsorption of the organic molecule. Alternatively, they may act to obscure the porous silicon and inhibit reaction of the organic molecules with the surface. A small $\mathrm{SiCl}^{-}$peak was also identified, with the presence of chloride ions due to the elimination of hydroxyl groups from a silica surface [22].

It is tempting to designate sulphur-containing peaks at 78.95 and $104.95 \mathrm{Da}$ to $\mathrm{SiOSH}_{3}^{-}$and $\mathrm{SiO}_{2} \mathrm{SCH}^{-}$. These can be resolved from overlaps with $\mathrm{SiO}_{3} \mathrm{H}_{3}^{-}$and $\mathrm{SiO}_{4} \mathrm{CH}^{-}$, respectively. However, the contaminant $\mathrm{PO}_{3}^{-}$ could overlap the former and $\mathrm{Si}_{2} \mathrm{O}_{3} \mathrm{H}^{-}$the latter. No other peaks existed to give evidence for contamination. These fragments, unique to the loaded region, could suggest bridging of the Si substrate and the positively charged methylene blue sulphur via a surface hydroxyl group. In aqueous solution, methylene blue exists as a positive ion. In a neutral $\mathrm{pH}$ environment, the acidic nature of the hydroxylated substrate surface leads to deprotonation of the silanol termini, thus providing $\mathrm{SiO}^{-}$groups that can readily interact with cationic species. Hence, chemisorption via oxygen bridging of the substrate silicon and the methylene blue's sulphur is quite feasible but requires additional scrutiny for confirmation.

While a small organic molecule (methylene blue) can therefore penetrate into the porous structure, as shown here, it is important that larger proteinaceous molecules can also infiltrate such structures. Confirmation of this, via the loading of papain, is given by the images in Figure 6. Spectra are included in the Supplementary Material, which can be found in the electronic version of this article. Peaks from $\sim 90$ Da onwards in the positive ion spectrum were largely of organic composition. Due to their position relative to the nominal mass units, it is believed that these peaks include a combination of higher order $\mathrm{C}_{x} \mathrm{H}_{\mathrm{y}} \mathrm{Si}$ as well as $\mathrm{C}_{\mathrm{x}} \mathrm{H}_{\mathrm{y}}$ and other $\mathrm{N}, \mathrm{O}$,
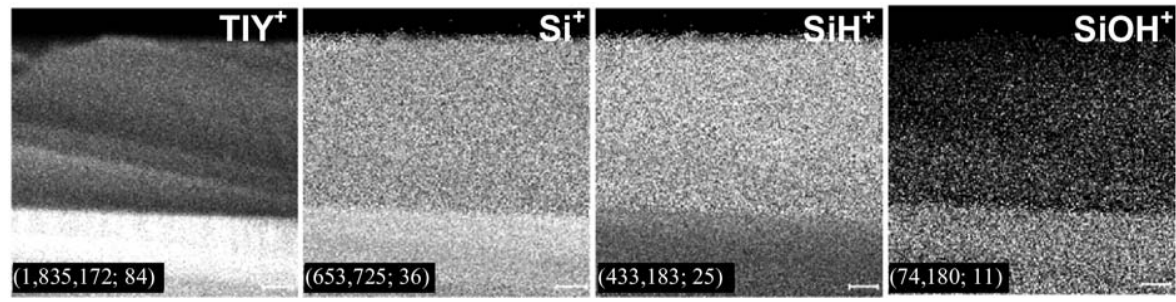

Figure 3. Positive ion images from a "blank" porous silicon cross-section. Note that topographic effects in the TIY are removed in the normalization of specific fragments. Numbers in parentheses indicate: (total ion counts; maximum count per pixel). Bar $=10$ micron. 


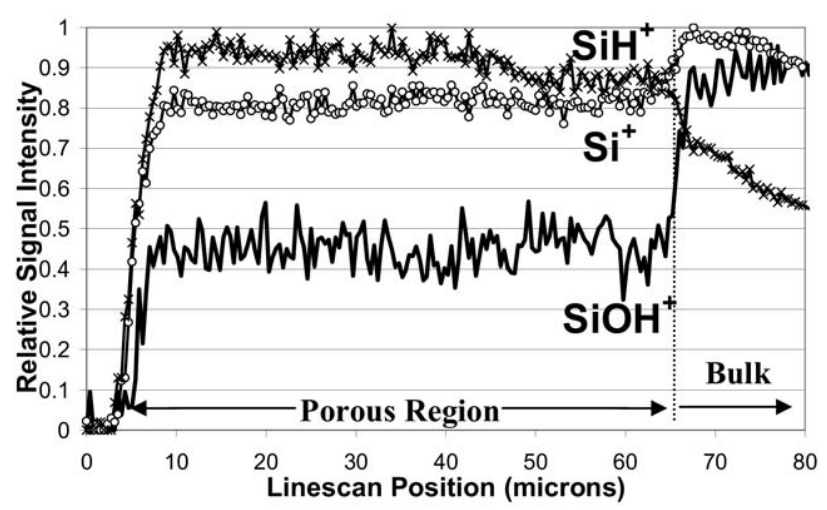

Figure 4. Line scans across the porous region of a blank wafer. The uniformity of these fragments suggest there is negligible change in the substrates chemical structure with increasing pore depth.

and S containing fragments. It is important to emphasize that these peaks were not present in the blank wafer, or the wafer exposed to milli- $\mathrm{Q}_{2} \mathrm{O}$, i.e., they originate due to the loading of the protein. Similarly to the methylene blue, the papain has preferentially been deposited into the deeper reaches of the porous zone.

There is some concern regarding whether the identification of organo-silicon fragments are correctly from the sample rather than recombination in the ion cloud above the sample surface during or after the sputtering process. Energetics from the bombarding primary ions may induce chemical transformation from the original arrangement. Francis et al. [23] observed results they believed to form from sub-surface aluminium combining with organic molecules in the sputtering process.

Upon surface treatments of silica, chemical interactions can become observable in SIMS spectra. Hua et al. [24] studied plasma interactions with the surface of nano-porous silica. Their studies suggested that partially treated surfaces exhibited interactions between the plasma and matrix. Intermediate etch products demonstrated ion induced reactions between the fluorocarbonplasma and the nano-porous silica resulting in $\mathrm{Si}_{\mathrm{x}} \mathrm{O}_{\mathrm{y}} \mathrm{F}$ fragmentation. This latter example is from a highly chemically reactive environment, however, Francis et al. [23] analyzed octadecylphosphonic acid monolayers deposited on mica via spin coating from solution. While the $\mathrm{Al}$ containing fragments appeared to be through a recombination process, they also observed fragmentation demonstrating the presence of ionic bonds between the substrate and deposited monolayer.

Other authors dismiss there being reasonable probability that recombination occurs in the sputter plume. Arafat et al. [25] concluded that fragments corresponding to $\mathrm{Si}-\mathrm{C}$ bonds in their SIMS spectra were indicative of covalent binding between the monolayer of alkyl chains and the silicon nitride substrate, as the low ion flux used in TOF-SIMS makes recombination above the surface an unfavorable process. Additionally, neutral ions may be ejected from the surface and, due to the internal kinetic energy, subsequently dissociate to form the detected ion. Hence, ions may form at a relatively large distance from the surface and, hence, by this means, there would be minimal opportunity for subsequent reaction to occur with other ions in the sputter plume.

Aubriet et al. [26] used an almost identical SIMS experimental arrangement as here, and compared fragmentation patterns of compounds versus mixtures of the same components. While their study was restricted to inorganic components, they suggest that the recombination of species sputtered in vacuum is not a significant occurrence. In contrast, the main pathway for ion formation, for oxide compounds in particular, occurs due to direct ejection of species into the vacuum upon ion bombardment. Therefore, while recombination cannot be entirely discounted, there exists reasonable evidence to support that the Si containing fragments acquired in these experiments do reflect chemical interactions between the porous silicon substrate and organic material loaded therein. Molecular dynamic simulations could be used to investigate this phenomenon more rigorously [27] and could be addressed in the future with greater computational power [28].

\section{Conclusions}

Evidence of newly formed $\mathrm{Si}-\mathrm{C}$ bonds and possible $\mathrm{Si}-\mathrm{O}-\mathrm{S}$ bonds has been presented here. Imaging has also shown the distribution of organics after deposition for assessing loading behavior by literally observing where the organic molecules reside. Porous structures are a viable substrate for loading small and large organic molecules. Loading dynamics as a function of time, concentration, and pore structure can be studied. In addition, due to the detection of organic, inorganic, and molecular fragments with TOF-SIMS, complimentary data obtained from infrared and X-ray photoelectron spectroscopy [29] can enhance understanding of the chemical mechanisms for adsorption.

Future application within the authors' host institution is anticipated, with more advanced primary ion sources. The organic signals will be significantly im-

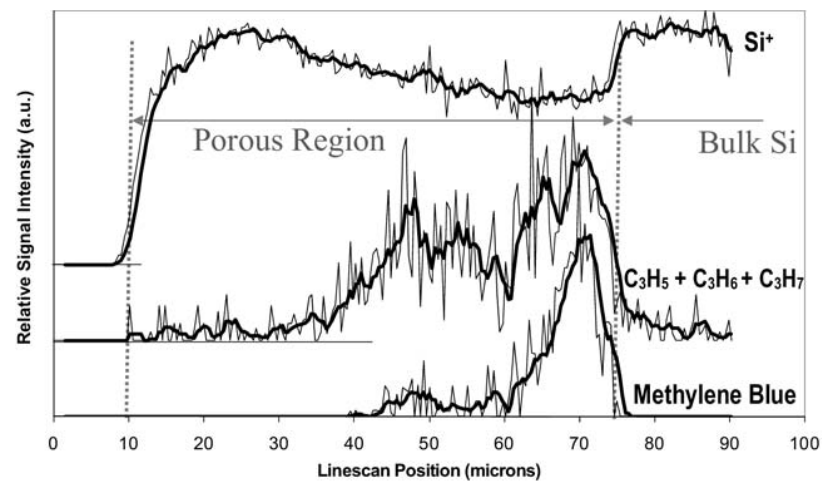

Figure 5. Line scans across the porous region of a methylene blue loaded wafer. The organic fragments indicate methylene blue has deposited in the deepest pore region. 



Figure 6. Positive TOF-SIMS images of the porous region of a papain loaded wafer. $\mathrm{Si}^{+}$and $\mathrm{SiH}^{+}$ highlight the bulk and porous regions while the organic fragments reveal the distribution of papain. Numbers in parentheses indicate: (total ion counts; maximum count per pixel). Bar $=10$ micron.

proved, for example, utilizing a $\mathrm{C}_{60}[30,31]$, Bi cluster [32], or Au cluster source [33], and coupled with multivariate statistical techniques [34, 35]. Such sources provide greater ionization efficiency and yields of larger and more indicative fragments [36]. Metal-assisted SIMS could also provide significant improvement [37]. These more informative sources may elude more chemical information regarding the binding mechanisms facilitating the adsorption of organic material in such substrates.

These results assist in understanding the interaction between probe molecules and the internal nano-porous network structure of a pSi wafer and, more importantly, provide information about the specific chemical versus physical binding. This is assisting in optimizing the loading of porous silicon particles with active pharmaceutical ingredients for delivery.

\section{Acknowledgments}

The authors acknowledge the Australian Research Council and pSivida Ltd. for financial support of this project through the ARC Linkage (LP0562379) scheme. Karyn Jarvis is acknowledged for her assistance in preparing samples for TOF-SIMS analysis.

\section{Appendix A. Supplementary Material}

Supplementary material associated with this article may be found in the online version at doi:10.1016/ j.jasms.2009.10.007.

\section{References}

1. Charrier, J.; Kloul, M.; Pirasteh, P.; Bardeau, J. F.; Guendouz, M.; Bulou, A.; Haji, L. Structural and Optical Studies of Porous Silicon Buried
Waveguides: Effects of Oxidation and Pore Filling Using DR1 Dyes. Opt. Mater. 2007, 30, 431-437.

2. Kilian, K. A.; Böcking, T.; Gaus, K.; King-Lacroix, J.; Gal, M.; Gooding, J. J. Hybrid Lipid Bilayers in Nanostructured Silicon: A Biomimetic Mesoporous Scaffold for Optical Detection of Cholera Toxin. Chem. Commun. 2007, 19, 1936-1938.

3. Pacholski, C.; Sartor, M.; Sailor, M. J.; Cunin, F.; Miskelly, G. M. Biosensing Using Porous Silicon Double-Layer Interferometers: Reflective Interferometric Fourier Transform Spectroscopy. J. Am. Chem. Soc. 2005, 127, 11636-11645.

4. Goh, A. S.; Chung, A. Y.; Lo, R. H.; Lau, T. N.; Yu, S. W.; Chng, M.; Satchithanantham, S.; Loong, S. L.; Ng, D. C.; Lim, B. C.; Connor, S.; Chow, P. K. A Novel Approach to Brachytherapy in Hepatocellular Carcinoma Using a Phosphorous32 (32P) Brachytherapy Delivery Device-a first-in-man study. Int. I. Radiat. Oncol. 2007, 67, 786-792.

5. Prestidge, C. A.; Barnes, T. J.; Mierczynska-Vasilev, A.; Kempson, I. Peddie, F.; Lau, C. H. Peptide and Protein Loading into Porous Silicon Wafers. Physica. Status. Solidi. (A) 2008, 205, 311-315.

6. Salonen, J.; Laitinen, L.; Kaukonen, A. M.; Tuura, J.; Bjorkqvist, M.; Heikkila, T.; Vaha-Heikkila, K.; Hirvonen, J.; Lehto, V. P. Mesoporous Silicon Microparticles for Oral Drug Delivery: Loading and Release of Five Model Drugs. J. Control Release 2005, 108, 362-374.

7. Prestidge, C. A.; Barnes, T. J.; Lau, C.-H.; Barnett, C.; Loni, A.; Canham, L. Mesoporous Silicon: A Platform for Delivery of Therapeutics. Expert Opin. Drug Delivery 2007, 4, 101-110.

8. Reffitt, D. M.; Jugdaohsingh, R.; Thompson, R. P.; Powell, J. J. Silicic Acid: Its Gastrointestinal Uptake and Urinary Excretion in Man and Effects on Aluminium Excretion. J. Inorg. Biochem. 1999, 76, 141-147.

9. Kempson, I. M.; Skinner, W. M. TOF-SIMS Analysis of Elemental Distributions in Human Hair. Sci. Total Environ. 2005, 338, 213-227.

10. Wu, L.; Lu, X.; Kulp, K. S.; Knize, M. G.; Berman, E. S. F.; Nelson, E. J.; Felton, J. S.; Wu, K. J. J. Imaging and Differentiation of Mouse Embryo Tissues by TOF-SIMS. Int. J. Mass Spectrom. 2007, 260, 137-145.

11. Mahoney, C. M.; Yu, J.; Fahey, A.; Gardella, J. A. Jr. SIMS Depth Profiling of Polymer Blends with Protein Based Drugs. Appl. Surf. Sci. 2006, 252, 6609-6614.

12. Ha, C.-S.; Gardella, J. A. Jr. Surface Chemistry of Biodegradable Polymers for Drug Delivery Systems. Chem. Rev, 2005, 105, 4205-4232.

13. Mahoney, C. M.; Roberson, S.; Gillen, G. Dynamic SIMS Utilizing SF Polyatomic Primary Ion Beams for Drug Delivery Applications. Appl. Surf. Sci. 2004, 231/232, 174-178.

14. Prestidge, C. A.; Barnes, T. J.; Skinner, W. Time-of-Flight Secondary-Ion Mass Spectrometry for the Surface Characterization of Solid-State Pharmaceuticals. J. Pharm. Pharmacol. 200, 59, 251-259.

15. Mitchel, R. R.; Chaiken, I. M.; Smith, E. L. The Complete Amino Acid Sequence of Papain. J. Biol. Chem. 1970, 245, 3485-3492.

16. Chiba, K.; Nakamura, S. Characterization of Silicon Oxide Films Using Positive and Negative Secondary Ion Mass Spectra. Appl. Surf. Sci. 2006, 253, 412-416.

17. Okuno, S.; Nakano, M.; Matsubayashi, G.; Arakawa, R.; Wada, Y. Reduction of Organic Dyes in Matrix-Assisted Laser Desorption/ 
Ionization and Desorption/Ionization on Porous Silicon. Rapid Commun. Mass Spectrom. 2004, 18, 2811-2817.

18. Alimpiev, S.; Nikiforov, S.; Karavanskii, V.; Minton, T.; Sunner, J. On the Mechanism of Laser-Induced Desorption-Ionization of Organic Compounds from Etched Silicon and Carbon Surfaces. J. Chem. Phys. 2001, 115, 1891-1901.

19. Delcorte, A. Organic Surfaces Excited by Low-Energy Ions: Atomic Collisions, Molecular Desorption, and Buckminster Fullerenes. Phys. Chem., Chem. Phys. 2005, 7, 3395-3406.

20. Weibel, D.; Wong, S.; Lockyer, N. P.; Blenkinsopp, P.; Hill, R.; Vickerman, J. C. A C 60 Primary Ion Beam System for Time of Flight Secondary Ion Mass Spectrometry: Its Development and Secondary Ion Yield Characteristics. Anal. Chem. 2003, 75, 1754-1764.

21. Brown, D. W.; Floyd, A. J.; Sainsbury, M. Organic Spectroscopy; John Wiley: Chichester, UK, 1988; pp 135-183.

22. Unger, K. K. Surface Chemistry of Porous Silica. In Porous Silica Its Properties and Use as Support in Column Liquid Chromatography; Elsevier Science: Amsterdam, 1988; pp 57-146.

23. Francis, J. J.; Nie, H.-Y.; McIntyre, N. S. TOF-SIMS Investigation of Octadecylphosphonic Acid on a Mica Substrate. Langmuir 2006, 22, 9244-9250.

24. Hua, X. Stolz, C.; Oehelein, G. S.; Lazzeri, P.; Coghe, N.; Anderle, M. Inoki, C. K.; Kuan, T. S.; Jiang, P. Plasma-Surface Interactions of Nanoporous Silica During Plasma-Based Pattern Transfer Using $\mathrm{C}_{4} \mathrm{~F}_{8}$ and $\mathrm{C}_{4} \mathrm{~F}_{8}$ /Ar Gas Mixtures. J. Vac. Sci. Technol. A 2005, 23, 151-164.

25. Arafat, A.; Giesbers, M.; Rosso, M.; Sudholter, E. J. R.; Schroen, K.; White, R. G.; Yang, L.; Linford, M. R.; Zuilhof, H. Covalent Biofunctionalization of Silicon Nitride Surfaces. Langmuir 2007, 23, 6233-6244.

26. Aubriet, F.; Poleunis, C.; Bertrand, P. Investigation of the Cluster Ion Formation Process for Inorganic Compounds in Static SIMS. Appl. Surf. Sci. 2003, 203/204, 114-117.

27. Delcorte, A.; Wehbe, N.; Bertrand, P.; Garrison, B. J. Sputtering of Organic Molecules by Clusters, with Focus on Fullerenes. Appl. Surf. Sci. 2008, 255, 1229-1234
28. Webb, R. P. What Do We Want from Computer Simulation of SIMS Using Clusters? Appl. Surf. Sci. 2008, 255, 1223-1228.

29. Jarvis, K. L.; Barnes, T. J.; Badalyan, A.; Pendleton, P.; Prestidge, C. A Impact of Thermal Oxidation on the Adsorptive Properties and Structure of Porous Silicon Particles. J. Phys. Chem. C 2008, 112, 9717-9722.

30. Weibel, D.; Wong, S.; Lockyer, N.; Blenkinsopp, P.; Hill, R.; Vickerman J. C. A $\mathrm{C}_{60}$ Primary Ion Beam System for Time of Flight Secondary Ion Mass Spectrometry: Its Development and Secondary Ion Yield Characteristics. Anal. Chem. 2003, 75, 1754-1764.

31. Poleunis, C.; Everaert, E. P.; Delcorte, A.; Bertrand, P. Characterization of Human Hair Surfaces by Means if Static ToF-SIMS: A Comparison Between $\mathrm{Ga}^{+}$and $\mathrm{C}_{60}^{+}$Primary Ions. Appl. Surf. Sci. 2006, 252, 67616764 .

32. Touboul, D.; Kollmer, F.; Niehuis, E.; Brunelle, A.; Laprevote, O. Improvement of Biological Time-of-Flight-Secondary Ion Mass Spectrometry Imaging with a Bismuth Cluster Ion Source. J. Am. Soc. Mass Spectrom. 2005, 16, 1608-1618.

33. Nagy, G.; Gelb, L. D.; Walker, A. V.; An Investigation of Enhanced Secondary Ion Emission Under $\mathrm{Au}_{n}^{+}(n=1-7)$ Bombardment. J. Am. Soc. Mass Spectrom. 2005, 16, 733-742.

34. Denman, J. A.; Kempson, I. M.; Skinner, W. M.; Kirkbride, K. P. Discrimination of Pencil Markings on Paper Using Elemental Analysis: An Initial Investigation. Forensic Sci. Int. 2008, 175, 123-129.

35. Denman, J. A.; Skinner, W. M.; Kirkbride, K. P.; Kempson, I. M. Organic and Inorganic Discrimination of Ballpoint Pen Inks by TOF-SIMS and Multivariate Statistics. Appl. Surf. Sci. 2009, DOI 10.1016/j.apsusc. 2009.09.066.

36. Mantus, D. S.; Ratner, D.; Carlson, B. A.; Moulder, J. F. Static Secondary Ion Mass Spectrometry of Adsorbed Proteins. Anal. Chem. 1993, 65, 1431-1438.

37. Heile, A.; Lipinsky, D.; Wehbe, N.; Delcorte, A.; Bertrand, P.; Felten, A.; Houssiau, L.; Pireaux, J.-J.; De Mondt, R.; Van Vaeck, L.; Arlinghaus, H. F. Metal-Assisted SIMS and Cluster Ion Bombardment for Ion Yield Enhancement. Appl. Surf. Sci. 2008, 255, 941-943. 